Meta

Journal des traducteurs

Translators' Journal

\title{
Training Translators and Interpreters in the USSR
}

\section{Aleksandr A. Barčenkov}

Volume 37, numéro 1, mars 1992

La traduction en Russie : théorie et pratique / Translation in Russia: Theory and Practice

URI : https://id.erudit.org/iderudit/001970ar

DOI : https://doi.org/10.7202/001970ar

Aller au sommaire du numéro

Éditeur(s)

Les Presses de l'Université de Montréal

ISSN

0026-0452 (imprimé)

1492-1421 (numérique)

Découvrir la revue

Citer cet article

Barčenkov, A. A. (1992). Training Translators and Interpreters in the USSR. Meta, 37(1), 163-168. https://doi.org/10.7202/001970ar

\section{Résumé de l'article}

On s'intéresse d'abord à ce qui différencie les écoles de traduction et d'interprétation de l'URSS de celles de l'Occident. On présente ensuite des grandes écoles de pensée soviétiques qui se penchent sur la pédagogie de la traduction. Après quoi, les quatre principaux champs d'étude enseignés dans les écoles de traductions en URSS sont traités. Enfin, on discute des difficultés rencontrées par les étudiants et les engeignants de ces écoles avant de proposer quelques solutions. 


\title{
TRAINING TRANSLATORS AND INTERPRETERS IN THE USSR
}

\author{
ALEKSANDR A. BARČENKOV \\ Maurice Thorez Institute of Foreign Languages, \\ Moscow, USSR
}

\begin{abstract}
Résumé
On s'intéresse d'abord à ce qui différencie les écoles de traduction et d'interprétation de l'URSS de celles de l'Occident. On présente ensuite des grandes écoles de pensée soviétiques qui se penchent sur la pédagogie de la traduction. Après quoi, les quatre principaux champs d'étude enseignés dans les écoles de traductions en URSS sont traités. Enfin, on discute des difficultés rencontrées par les étudiants et les engeignants de ces écoles avant de proposer quelques solutions.
\end{abstract}

What makes a good translator?

What hierarchy of the basic components of translator training - language skills, cultural awareness, and translation skills - is the surest way to success?

How should each of these components be taught?

These and many other questions have been worrying the best minds in translation pedagogy for years, with the various translation schools in the world rearranging their priorities in search of the perfect formula.

Unlike many translators' schools in the West, whose admission requirement is competence in at least one foreign language, training of translators in the Soviet Union incorporates an extensive language proficiency program combined with a course in translation proper. Another important difference is in the numbers of professionals to be trained and the scope of their training: the goals of teaching interpreters and translators in the USSR are defined by the need to train a large number of people able to cope with jobs in a variety of fields requiring translating, abstracting and precis-writing as well as public relations skills in dealing with foreign companies and businesses. These differences pose a number of principal problems in translation didactics and foreign language teaching and also in institutional administration.

The approaches to training of translators and interpreters in the Soviet Union are defined by the existing and constantly growing needs in the various fields of science, technology, commerce, industry, mass media and arts. New trends in glasnost and the greater openness of Soviet society create better job opportunities for professionals in the field and at the same time impose more rigorous demands on the entire system of education.

The history of education for translators and interpreters in the USSR begins in the early 1940 s when the first specialized departments were set up at the more important language schools. This was due to the need to train translators for the war effort. Later these departments evolved into the major peace-time colleges training undergraduates for a variety of jobs in oral and written translation and inter-cultural communication.

Today there are four university-level translation schools in the USSR. They form major divisions at institutes of foreign languages in Moscow, Minsk, Gorky and Baku. These institutes train over 300 translators and interpreters in fourteen languages each year $(140,80,60,30$ respectively). They provide a five-year training programme and award 
degrees roughly equivalent to a Master of Arts. The institutes offer a choice of European and Oriental languages, with Moscow, Minsk and Gorky specializing mostly in European languages and Baku concentrating on Oriental languages.

Institutes of foreign languages in Moscow and Tbilisi also offer a two-year professional training course at a more advanced level. The course has been designed to provide training for those who are already working in the field and need to improve their skills in specific areas (conference interpreting, consecutive interpreting and written translation). The Moscow School of Advanced Training for Translators and Interpreters at the Maurice Thorez Institute of Foreign Languages gives training in consecutive and simultaneous interpretation taught as a separate speciality and also in written translation in economic, technical, legal, literary and sociopolitical fields. The school in Tbilisi was originally started for simultaneous interpreters in foreign languages/Georgian language combination, but today it is passing through a period of expansion with plans to add a written translation course in a wider variety of languages to the existing programme. The advanced training schools which represent the highest level of professional education in the field admit students who have already had five years of university level studies in foreign languages.

Besides, a top-level instruction program is provided by the United Nations Translation School at Maurice Thorez in Moscow which trains approximately 30 translators and interpreters yearly for future work in the UN specialized agencies and organisations.

The Maurice Thorez Institute also offers three-year graduate research programs which lead to advanced scholarly degrees (Kandidat Nauk) conferred on those who have passed all the examinations and successfully presented and defended their dissertations. Research at a more advanced level is crowned by a top degree of Doctor of Linguistics (Doctor Nauk). Theory of translation, which has been pioneered and promoted by the leading Soviet professionals in the field including Andrei Fedorov, Yakov Retsker, Victor Rozentveig, Leonid Barkhudarov, Aleksandr Sweitser, Vilen Komissarov and Gelyi Chernov, serves as a basis for all the training programs offered. The theoretical input is very important for the training methodology and practice and a course in the theory of translation is incorporated into the curricula of translation schools at all levels.

In addition to professional training, several universities and technical institutes provide brief courses in translation for undergraduates wishing to combine their future professional interests with part-time translation jobs. Initial translation skills are also developed in specialized secondary schools which offer an extended course in foreign languages.

An overview of the existing system shows that its core is made up of foreign language institutes. These give a basic education leading to a five-year degree in translation which in fact includes an extensive language program. Thus a university-level degree in translation in practice includes an advanced degree in languages. The bringing together of the two programs under one heading poses a fundamental problem of correlating language instruction and translation teaching which often clash in methodology and practice. Therefore translation training based on a five-year program requires a curriculum that would try to resolve the constant conflict between these two components.

The philosophy currently prevailing in the field of translation pedagogy lays the stress on dividing the training process into two stages: language training and translation training. It should be noted that this division is largely theoretical, for in practice the two stages are often viewed as one due to the fact that a five-year language instruction course runs parallel to a three-year course in translation. 
According to this approach the training in translation can begin only after the student has reached a sufficiently high level of linguistic competence, that is the student is expected to possess the skills adequate for a near-native interaction in foreign languages. A standard Soviet curriculum requires a highly advanced level in two foreign languages. Then the translation professionals take over and begin their specialized training alongside language instructors who continue their course. The benefits of this approach are obvious: translation instructors need not spend any time on traditional language teaching problems and so, depending on the students' natural abilities and aptitudes, one can reliably train a higher or average-level translator within five plus three years of study telescoped into a five-year course. The advocates of this approach see translator training translation as a separate subject and regard the students' language proficiency as the responsibility of language instructors. However, in an educational environment which offers very few opportunities of study tours abroad and very limited exposure to foreign cultures and native teachers this approach has a number of flaws seriously affecting the quality of training.

Another school of thought (Gorky, Minsk) promotes an integrated approach to the training of translators and combines it with a degree in language teaching. The advocates of this school believe that one can acquire sufficient translation skills within an extensive language course. In accordance with this, the training process is organized so as to integrate language instruction and translation training into a uniform program. This gives a clear advantage to a student with an initially low language command, who can work either as a language instructor or a translator after graduating. At the same time, being a primarily language-oriented course, it falls short of providing sufficiently advanced translation training to meet the requirements of high-level professional jobs. However, this places higher demands on the faculty, for they have to be versatile both in language instruction and translation teaching and be able to merge and readjust their activities according to the needs of the students.

Ironically, curriculum developers in different schools tend to overlook this major conflict of opinion and come up with a plan that structurally shows an almost complete similarity of components irrespective of the resulting degree.

A typical curriculum of a five-year translation and interpretation course will include three major groups of subjects: socio-political, general linguistics and language study, and translation proper. These groups of subjects are not equal in terms of contact hours, although the importance of each for future professionals has been proven to be indisputable.

The socio-political disciplines (11 per cent of the contact-hour total) are taught throughout the duration of the course and generally include the political economy, philosophy, general history, Soviet law and history of religion. It should be noted that this group of subjects is undergoing a major revision today as new and less orthodox sociopolitical disciplines are being added to the curriculum. They are replacing the more traditional and simplified versions of Marxism-Leninism and are designed to give the future professionals a broader outlook and also serve a more mundane purpose of relating this theoretical knowledge to the day-to-day translator's work.

The training in general linguistics (10 per cent of the contact-hour total) has a dual objective of forming a theoretical linguistic base for future practical applications and a thorough training in the basic language skills. In the first two years undergraduates take a course in introduction to general linguistics complemented by a practical course in Latin. From the third year onwards, undergraduates take courses in lexicology, theoretical grammar, and history of the first foreign language, all in about equal numbers of contact hours. Stylistics taught for two semesters (full academic year) in the fourth year is 
directly geared to the needs of translation and includes a theoretical and practical study of different styles and registers by contrasting them with their counterparts in the native tongue. All these theoretical disciplines provide a basis for a course in the theory of translation which starts in the third year with a general theoretical overview of the existing approaches to translation and is continued in the fourth year with lectures in applied translation theory. Theoretical disciplines also include an extensive course in the literature, history, culture and geography of the first and second foreign languages reinforced by various optional courses including cultural studies, psycholinguistics, crosscultural communications, etc.

The basic foreign languages skills ( 40 per cent of the contact-hour total) are taught throughout all five years. They can start at either beginners' or intermediate level depending on whether or not the student has taken this foreign language in high school. Students are typically required to take two foreign languages and can add other languages if they wish. It should be noted, however, that the second foreign language begins in the second or third year and accounts for roughly half the time spent on the first language and yet the course is structured and designed in such a way that it provides enough knowledge and skills for professional translation work. The foreign language instruction follows different patterns. The Maurice Thorez Institute emphasizes a structured approach where the course is broken down into a set of different subjects organized into four major groups: speaking and writing, reading and oral comprehension. These are further divided into phonetics, grammar, text interpretation, language of the mass media, conversational skills, composition and essay writing. In Gorky the emphasis is placed on an integration of practical linguistic subjects into a uniform course, where various language skills are developed without identifiable boundaries between grammar, reading or oral comprehension class.

A practical course in the Russian language takes up four semesters and serves as an important element of translator training.

A course in translation (19 per cent of the contact-hour total) includes theoretical and practical subjects with an emphasis on practical skills. The theoretical subjects look at the semantic and pragmatic aspects of translation and also general and specific regularities between the languages involved. Practical classes teach students to interpret and analyze the text in terms of translation strategies. This is combined with exercises in abstracting and précis-writing. The course begins with a series of exercises in elements of written translation, paraphrasing, and leads to sight translation, consecutive and simultaneous interpretation. The emphasis is placed on written translation from two foreign languages into the native tongue. Materials for translation include texts on sociopolitical, economic, scientific and technical subjects. Consecutive and simultaneous interpretation are taught using primarily public speeches and conference papers in similar fields. The share of time allotted for simultaneous interpretation is relatively small and therefore the course can only be viewed as an introduction to this advanced translation skill.

Although the problems mentioned above are hidden in the curriculum description they become clear in the classroom and make themselves felt in the future professional careers of the graduates. Taken to extremes, the problems mentioned above represent a situation where either translation skills are sacrificed at the expense of language training or language training is sacrificed for the sake of translation. In practice this means that in the first case translators acquire advanced language skills, but lack confidence when it comes to actual translation. In the second case, while well-versed in translation techniques, translators lag behind when it comes to using the foreign language in various functional situations. Many of the difficulties involved in both cases are due to the 
existing orientation of language teaching. It is heavily cognitive in nature and lays emphasis on the language system with subsequent introduction of the students to functional and communicative language uses. This approach usually gives very good results if the final requirement is language teaching or other language-related jobs outside professional translation. But in the context of translator training the students who have mastered the language system and have familiarized themselves with its basic functional uses (neutral expression in semi-formal register) find it very difficult and sometimes almost impossible to readjust their language skills to the requirements of generating a diversity of texts in different registers, styles, and communicative situations. Therefore they concentrate on various translation devices as the only possible survival technique and only the brightest and most gifted ones can overcome this difficulty and become good translators. Even in situations when the student's initial level of language is very high this contradiction between the system-oriented approach and a text-oriented one decreases the efficiency of translation training. Theoretically, the system-oriented approach in language teaching as a basis for a translation course could be used if students could have more time for language learning or if they spent a year or two abroad to acquire the necessary skills in functional language uses. This is in fact done at some leading translation schools in the West, that can well afford to do this given the small number of students to be trained. In our context, however, extending the language program beyond five years of study is unfeasible.

Therefore one can either keep on teaching language as a system, then add a translation course and hope for the best, or else undertake a profound revision of the whole language teaching concept in translation training.

Proceeding from the assumption that the basic ability that underlies that translation process is the ability to generate diverse texts varying in communicative structure, style, register and pragmatic aspects, it is reasonable to suppose that the core of language training for translators should stress the multifunctional nature of language means. This will help the future translator to correlate the acquired variety of language expression with the communicative situation and produce target language texts that adequately reflect the current usage and language norms accepted by the language community. In other words, this kind of training should help students not only master the variety of language uses, but give them the ability to select the relevant form of expression depending on the communicative context. Placing the text at the centre of language training does not exclude mastering the rules of the languages system. But these rules, which hardly ever go beyond the sentence level, should always be accompanied by text analysis in order to show the students how these rules are to be applied in actual communicative contexts. Many of the problems involved in this are owing to the inadequate use of translation as a teaching device at the early stages of language instruction. It is an accepted practice to use translation into a foreign language as an auxiliary technique to introduce new grammar and vocabulary or to test their acquisition. This practice has a number of serious faults: first of all, it runs against the established translation principles where translation into a foreign language is viewed as a more difficult task than translation from a foreign language. Secondly, and, perhaps, even more importantly, these translation exercises, which are in fact nothing more than substitution tables in disguise (cf. the numerous exercises where students are expected to translate sentences using a prescribed grammar form or lexical unit), are grossly misleading: they create the illusion of text-generating activities while developing only form-generation skills. This is only one example of how the means and the objectives of training are mixed up with a resulting misconception of the nature of translation as a specific type of speech activity. The essence of translation lies in overcoming differences between the 
systems of two languages, language norms and cultural backgrounds. But it would be wrong to conclude that one can teach the students possible equivalents in both languages and present them as translation. Language instruction for translators should stress the differences that exist between the languages rather than orienting students towards artificial one-to-one relationships between language units and structures in the native and foreign tongues. In other words, one should stress the principle of variety in language means and forms of expression and ways to reflect this in translation. It is important that students perceive translation as a medium of instruction. Translation as a medium of instruction should not be treated in a simplified version of the grammar-translation approach. It is rather a comprehensive method that would help expose students to translation viewed as both the means and objective of their training. It should be noted, however, that demonstration of differences between the two language systems and acquisition of skills to overcome these differences do not constitute the final goal of translation awareness in language skills. Other components of the training process should aim at neutralizing the interference due to the differences between the usage and norms of the foreign and native languages, thus creating conditions for a deeper semantic analysis of the text at later stages of instruction.

Putting these ideas into practice within a foreign language course may well give students the essential translation awareness, that is teach them to view a text as a set of identifiable translation problems which later he or she will be taught to solve by using adequate translation strategies. This innovative approach to language and translation training is already being practiced by some of the more perceptive instructors. Adopting the translation awareness approach to translator and interpreter training as a standard curriculum principle is one of the major priorities of Soviet translators' schools today. 